\title{
Japan: from rags to riches, but where to go next?
}

Tokyo. In August 1945, when Japan's military finally surrendered, most of the country's urban centres lay in ruins, the economy was shattered and the populace was literally starving. The subsequent Allied occupation, which lasted until a peace treaty was signed in 1953, transformed the administrative, social and economic institutions including universities and private and public research institutes.

The occupation, combined with General Douglas MacArthur's democratizing reforms, became the biggest single influence on Japanese science in the immediate postwar years. As in Germany, the occupying US Army, keen to end Japan's potential to wage war, banned research in aviation, radar and isolation of isotopes, even dumping the country's three cyclotrons in the ocean.

But other changes were more constructive. The university system was extensively reformed, resulting in the building of regional universities. Enrolments at universities increased 25-fold between 1945 and 1994, from 100,000 to $2,480,000$, and the number of researchers in Japan increased sevenfold from 82,000 in 1960 to 558,000 in 1994 , many of them engineers who helped to power the growth of Japan's industry.

Nevertheless, today, entrance to Tokyo University and the handful of other former imperial universities, as well as to a few of the older private universities such as Waseda and Keio, is still the principal goal of Japan's school-leavers.

Furthermore, with the student-age population in decline after peaking at 2 million in 1992, the gap between these élite old universities and the hundreds of new ones is likely to widen, at least in research, as the government plans to target more money at the best university research groups.

Up to the 1960s, post-war science focused on the importation and assimilation of foreign technologies, to aid economic reconstruction. By the mid-1950s, when Japan's gross national product (GNP) had been

\section{IMAGE UNAVAILABLE FOR COPYRIGHT REASONS}

restored to its pre-war levels, the government set up the Science and Technology Agency (STA), and initiated research programmes in nuclear power.

'Common use research centres' were created such as the Institute for Cosmic Ray Research at Tokyo University, and the Institute for Fundamental Physics, attached to Kyoto University. These centres at last provided Japanese academics with access to world-class equipment too expensive for individual universities.

This was followed in the 1970s and 1980s by the setting up of several institutes for joint university use, such as the Institute of Space and Astronautical Sciences (ISAS) which formerly belonged to Tokyo University. Several of these institutes, of which there are now more than a dozen, have achieved international recognition as centres of excellence, but they have tended to drain money away from research in the universities themselves.

Like much of the Japanese economy, science and technology are supervised and controlled by the national government. Academic staff at national universities, for example, arc all direct employees of the Ministry of Education, Sport, Science and Culture (Monbusho).

Minoru Oda, former director general of ISAS, and also a past president of the Institute of Physical and Chemical Research (RIKEN), praises this close relationship. He says that while it is easy to criticize the government, the success of post-war Japanese science owes much to the direct support of government ministries.

Rapid growth of the Japanese economy from the 1960 s onwards was matched by rapid increases in spending on research. Total spending on research was just $¥ 184.4$ billion (US $\$ 1.84$ billion at current exchange rate) in 1960 , only 1.1 per cent of GNP. But by 1990 this had risen to $¥ 12,100$ billion, or 2.78 per cent of GNP.

But after five decades of economic growth achieved largely by adapting and improving technology introduced from overseas, Japanese science is headed for change that should lead to increased budgets for fundamental research.

The white paper on science and technology, published last year by the STA, states that Japan, having caught up with other advanced countries in the area of technology, no longer has models to follow and must now create new knowledge and new technologies of its own.

Recent supplementary budgets, Bombed out: RIKEN had to rebuild after war damage. for example, have contained funds

\section{Revival for RIKEN}

THE fortunes of RIKEN have, in a way, mirrored those of Japanese science. Severely damaged by bombing in the last year of the war, RIKEN was dealt a further blow when the Americans tossed its cyclotron into Tokyo Bay.

RIKEN, which had been a thriving and largely self-supporting centre for fundamental research since its foundation in 1917, was further weakened when it was stripped of its associated companies as part of general headquarters' policy of breaking up the zaibatsu or giant conglomerates which were seen as potentially dangerous to democracy because of the concentration of economic power that they represented. RIKEN struggled along for some years in a very poor state.

Help arrived, however, for RIKEN in the form of Kakue Tanaka, who became prime minister in 1972 and who as a young man had worked for the president of RIKEN. In a move supported by the many academics who remembered RIKEN's heyday, the government revived RIKEN with financial support, bringing it back to life in its present form as a largely government-supported research institute.

RIKEN is praised by one of its former presidents, Minoru Oda, as being "more academic than academia". Another special feature is its broad focus on all areas of science from fundamental basic research right through to industrial applications. Now, RIKEN is flourishing, with branches in Tsukuba Science City, Sendai and Nagoya as well as the main campus in northwest Tokyo. S. B.

for research grants available to researchers across the whole spectrum of public sector research.

Buffeted by recession, the effects of a strong currency and beset by challenges to Japan's technological lead in many areas of industry, policy-makers are betting that basic research can help to revive the faltering economy. This is in stark contrast to most other developed countries where the emphasis is now on 'strategic' research with clear socio-economic goals.

Indicative of this trend are the recently passed Basic Science and Technology Law, which guarantees government support for fundamental research, and a newly proposed law to establish a high-level committee to analyse and assess existing and proposed research projects.

If these developments indicate a genuine commitment to supporting innovative research, there can be no doubt that Japan, which rose so spectacularly from the ashes of defeat, will soon be making some extraordinary discoveries.

Stephen Barker 